\title{
How well do Chinese corporate responsibility expectations map onto an international corporate responsibility scale?
}

\author{
Manfred Max Bergman - Lena Berger • Klaus Leisinger • \\ Jiaqi Zhang • Baocheng Liu · Zinette Bergman
}

Published online: 25 November 2015

(C) Springer-Verlag Berlin Heidelberg 2015
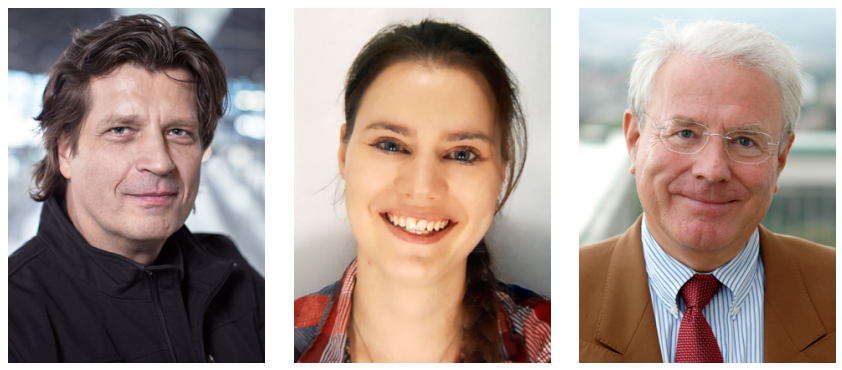

Manfred Max Bergman Lena Berger
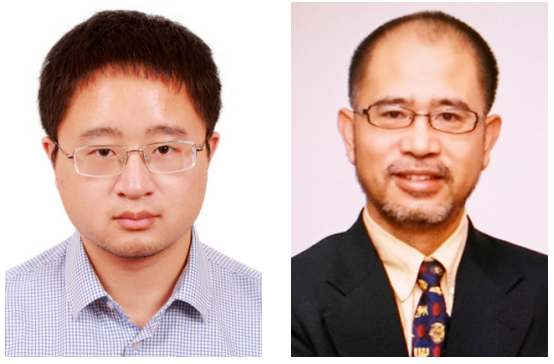

Jiaqi Zhang

\section{Klaus Leisinger}

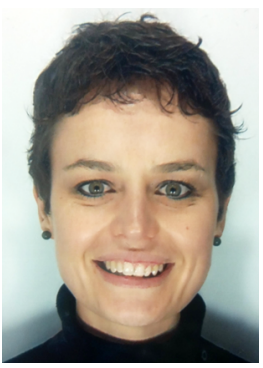

Zinette Bergman

*Manfred Max Bergman is extraordinary Professor at the Universities of the Western Cape and the Free State, South Africa. Visiting Professor at the University of International Business and Economics, Beijing, China

M. M. Bergman $(\bowtie) \cdot$ L. Berger $\cdot$ K. Leisinger $\cdot$ Z. Bergman Social Research and Methodology Group, University of Basel, Basel, Switzerland

e-mail: Max.Bergman@unibas.ch

K. Leisinger

Global Values Alliance Foundation,

Basel, Switzerland

"[W]e can no longer remain indifferent [to China], because circumstances are bringing every day more clearly into view the important part China must play in the changes that have become imminent in Asia, and that will affect the security of our position and empire in that continent. A good understanding with China should be the first article of our Eastern policy, for not only in Central Asia, but also in Indo-China [....] her interests coincide with ours and furnish the sound basis of a fruitful alliance."

(Boulger 1893)

Established corporate responsibility (CR) concepts and scales tend to originate in developed economies and, as a consequence, are strongly influenced by Western, especially North American, British, and Australian worldviews, value premises, organizational culture, market logics, socio-economic sensitivities, and historical and political developments. Due to the powerful link between the prevailing CR discourse and its Western context, we examine here how appropriate CR-relevant logics are for non-Western, especially emerging economies, which, viewed from the perspective of Western cultures, are often presented as lacking in sensitivity or sophistication in business ethics generally, and CR specifically. Any standard developed in one culture and applied to another is likely to reveal shortcomings in the latter and an ostensible superiority, moral and otherwise, in the former. This does not mean, however, that business eth-

J. Zhang $\cdot$ B. Liu

University of International Business and Economics,

Beijing, China

\section{Z. Bergman}

University of the Witwatersrand,

Johannesburg, South Africa 
ics in general and CR debates in particular need to succumb to a shallow but dangerous cultural relativism.

In view of globalizing economies and societies, drawing a line or, more appropriately, an acceptable and culture-sensitive corridor of responsible corporate practices is becoming more urgent than ever. Despite the dominance of Western models within the CR discourse and the prominent role foreign companies play in establishing the concept in modern China, the unique characteristics of the national context may nevertheless affect the development and understanding of CR. This is implied by Wang and Juslin, when they state that "Western CSR concepts cannot fit the Chinese market well" $(2009$, p. 435). A variety of indicators suggest context-specific developments of CR-relevant concepts in China. For example, Chinese culture and philosophy, especially in the Confucian and Taoist traditions, affect business ethics, and they contribute to the formation of specific ethical position such as the Harmony Approach (Wang and Juslin 2009), the Confucian Firm (Ip 2009), and the Good Person Culture (Lu 2009). The impact of the Chinese context is also evident in CR practices. Philanthropy - often regarded as a "nice to have" but insignificant or even problematic dimension in the Western discourse on CR-plays an important role in Chinese corporate engagement, due in part to its philosophical and historical links to Confucianism and communism (Bergman et al. 2015). More fundamentally, there is evidence for context-specific understandings of the meaning of CR. Studies of CR in China often operate with categories uncommon in the Western discourse, for example promoting state development (Peng et al. 2007), political tendency (Su 2013), social stability, development, and progress (Xu and Yang 2008). Even well-established CR dimensions, such as economic, legal, social, and environmental responsibilities may be perceived in divergent ways (ibid).

Given the implication of a culture-specific and contextsensitive representation of CR in China, we wonder how well Western scales, even if they have been formally tested in non-Western contexts, account adequately for Chinese perspectives. In this study, we explore empirically how well Chinese corporate responsibility expectations map onto an international corporate responsibility scale.

\section{Theoretical background}

Based on an extensive literature review, Quazi and O'Brien (2000) developed a two-dimensional model of CR. The first dimension differentiates between a "narrow responsibility" position, which limits the responsibilities of corporations to profit maximization and shareholder value creation based on the provision of goods and services, and the "wide responsibility" position, which extends to "expectations of society in areas such as environmental protection, commu- nity development, resource conservation and philanthropic giving" (ibid, p. 35). The second dimension refers to the consequences of $\mathrm{CR}$ in that one end of the continuum represents costs associated with CR programs, while the other emphasizes their benefits. The two dimensions are assumed to be orthogonal, and each quadrant refers to a CR type, namely the classical, socioeconomic, modern, and philanthropic "view". According to the classical view, "there is no provision to look beyond a narrow view of profit maximization as it is seen to generate a net cost to the company without any real benefit flowing from an activity" (ibid, p. 36). The socioeconomic view posits that certain social interventions may be beneficial for the corporation although it rests on a narrow responsibility position (ibid). The philanthropic view refers to businesses engaging in CR despite the perceived costs associated with these activities (ibid). The modern view - the label and language used to describe this quadrant clearly reveals the authors' preferential position among the four - "captures a perspective in which a business maintains its relationship with the broader matrix of society where there are net benefits flowing from socially responsible action in the long run, as well as in the short term" (ibid; cf. Carroll 1991).

The theoretically derived model was tested with a questionnaire, in which 320 CEOs of corporations from the textile and food industry in Australia and Bangladesh were asked to respond to 25 statements associated with this typology. The results of this study supported the two-dimensional concept of $\mathrm{CR}$, and it revealed further that the most prevalent types represented in the study were the classical and the modern view (ibid). As a suitable representative of a CR scale, Quazi and O'Brian's typology was used to investigate the extent to which corporate responsibility expectations in China map onto Western understandings of CR.

\section{Methods}

Data for this project included short essays based on the question "In your opinion, what are the responsibilities of large corporations?", as well as questionnaire responses based on the 25 item scale by Quazi and O'Brien (2000). 80 business and economics students at an advanced Master's or doctoral level from a first-tier university in China participated in our study. All data were collected in Mandarin and translated into English for analysis to assure that the respondents could express themselves without linguistic constraints, i.e. we translated the questionnaire items from English into Mandarin, and the essays written in Mandarin into English.

The data were analyzed using a mixed methods approach, consisting of four parts. In the first, we identified the CR dimensions based on a hierarchical cluster analysis of the 25 items according to Spearman's and Kendall's rank cor- 
relation. In the second and third parts, the results of the hierarchical cluster analysis were used to identify respondents holding opposing views according to Quazi and O'Brien's CR typology. The content of the essays of these individuals was analyzed based on a Content Configuration Analysis (Bergman 2011; Bergman et al. 2011). Finally, we applied multidimensional scaling to analyze the association between the location of the selected respondents based on Quazi and O'Brien's CR typology and the corresponding essay content on corporate responsibility expectations.

\section{Results}

Step 1: Hierarchical cluster analysis

A hierarchical cluster analysis of the 25 statements from the Quazi and O'Brien CR typology revealed two main clusters: The first consists of statements relating to the broad view on $\mathrm{CR}$, such as "Business has a definite responsibility to society apart from making a profit" and "Business should realize that it is a part of the larger society and therefore it should respond to social issues", as well as statements emphasizing the benefits of CR, such as "Contributing to the solution of social problems can be profitable for business" and "Social responsibility is an effective basis for competing in the market." The second cluster includes statements relating to the narrow view on $\mathrm{CR}$, such as "Asking business to be involved in any activity other than making profit is likely to make society worse off rather than better off" and "It is unfair to ask business to be involved in social responsibility programs as it is already doing so by complying with social regulations," as well as statements referring to the cost of social involvement, such as "It is unwise to ask business to fix social problems created by others and which have no profit potential" and "A business that ignores social responsibility may have a cost advantage over a business that does not". These two clusters correspond with the classical and modern view as described by Quazi and O'Brien. Accordingly, the cluster analysis reveals a similar structuring of responses in China, compared to the one found in Australia and Bangladesh. A quantitative study would have concluded at this point that there are two opposing views on $\mathrm{CR}$ in China: the classical view versus the modern view.

Steps 2 \& 3: Identification of respondents holding opposing views/Content Configuration Analysis

In the next analysis step, we identified the respondents who scored highest on the questions of each of the two clusters to examine their CR position in relation to Quazi and O'Brien's modern and classical views. Contrary to what we would expect based on the Quazi and O'Brien CR typology (respondents holding the classical view focus on profit generation, while those holding a modern view have a broader CR view), we find that both groups emphasize both economic and social responsibilities, such as enhancing social wealth, social benefits, public welfare, employment generation, and giving to society. Nevertheless, they concurrently emphasize responsibilities associated with increasing market share and value creation. In contrast, environmental responsibilities are nearly absent in both groups. When mentioned, they tend to be subordinated to socioeconomic issues. For example, respondents holding the modern view wrote:

- The first responsibility is innovation, which can promote the progress of science and technology and escalate labor productivity. The second responsibility is creating economic value, which can promote the growth of social wealth. The third responsibility is to solve the employment problem in order to maintain social stability; the fourth responsibility is to change people's lifestyle to make it more convenient and efficient. [...] Large corporations occupy much more social resources, so they should take on relevant social responsibilities; large corporations are one of the important driving forces to promote social development. (No. 16, high on cluster 1)

- Business responsibilities: develop the company to the largest corporation in that area. Responsibilities to staff: pay more attention to staff. Build up a close relationship between company and employees, make them believe they can benefit only when the company benefits. Social responsibilities: pay more attention to society; be active and participate in public welfare activities; gain more recognition from the public, build up trust from society; make the public aware of the corporation's social responsibilities. (No. 61, high on cluster 1)

In comparison, respondents holding the classical view wrote, for example:

- In my opinion, large corporations' higher responsibility is social responsibility. Large corporations have significant influence on social operations, some of them even control the distribution of state resources. Therefore, besides economic benefit, large corporations should also take social benefit into consideration when making decisions. Because large corporations have significant influence on social operations. I think that the government should encourage corporations to actively invest into social responsibility, thus corporations will increasingly take on more responsibilities. (No. 14, high on cluster 2)

- Undertake social responsibility, large corporations should create more job opportunities and wealth for society; create more value for shareholders and employees; under the circumstances in China, corporations should 
act as the leaders in the development of industry, inspire more people to make their own business. Corporation's profit comes from people, so people should absolutely benefit from that. Corporations are difficult to develop without the support from the nation and people. The corporation's main mission is to create value for its shareholders. If corporations lack the support from employees, it will be hard for them to achieve sustainable development. The policy from China's economic reform states: "to allow some people to get rich first, the rich will have to support the poor, at the end to achieve common prosperity." The nation has provided large corporations many favorable policies to support their development, which is why corporations should be held up as a model to fulfill social responsibility, as they return to society. (No. 79, high on cluster 2)

Overall, the comparison of the essays reveals great similarities in content between the classical and the modern view. Respondents combine both economic and social responsibilities on CR, even when they score high on the classical view. This finding contradicts Quazi and O'Brien's model, specifically because these two views are theorized to be located at opposite ends of the two dimensions. Generally, advanced Chinese management and economics students display a wide socioeconomic horizon such that they emphasize indirectly the interdependence between economic and social responsibilities of corporations, and they recognize the pivotal role corporations play in relation to economic and social development of the nation.
Step 4: Mapping the Quazi and O'Brien CR typology onto corporate responsibility expectations

To better understand the content and relations between the classical and the modern view from a Chinese perspective, we projected them onto the mental map of themes associated with corporate responsibility expectations. This was accomplished by Hermeneutic Content Analysis (HCA, Bergman 2010), which includes an extraction of themes from the essays based on a Content Configuration Analysis and a subsequent Multidimensional Scaling of the themes in geometric space (Fig. 1).

Overall, the map reveals three perspectives within the essays on CR, namely CR goals, CR practices, and theoretical foundations of $\mathrm{CR}$. CR goals include overarching societal goals such as achieving social development and stability, improving and sustaining the economy, fostering sustainable development, including working on social problems (i.e. societal hot spots such as corruption). Corporations ought to be responsible by engaging in specific CR practices, such as innovating, giving to society, creating values, taking care of employees, protecting the environment, and generating wealth for society. Accordingly, economic development is strongly connected to social development in our Chinese data, such that even shareholder profits and value creation are connected to employee wellbeing and giving to society. Environmental concerns play a marginal role, mainly referring to current air and water pollution levels generated by large corporations. In other words, environmental pollution plays a subordinate role to socioeconomic
Fig. 1 Mapping corporate responsibility expectations - classical and the modern views of $\mathrm{CR}$

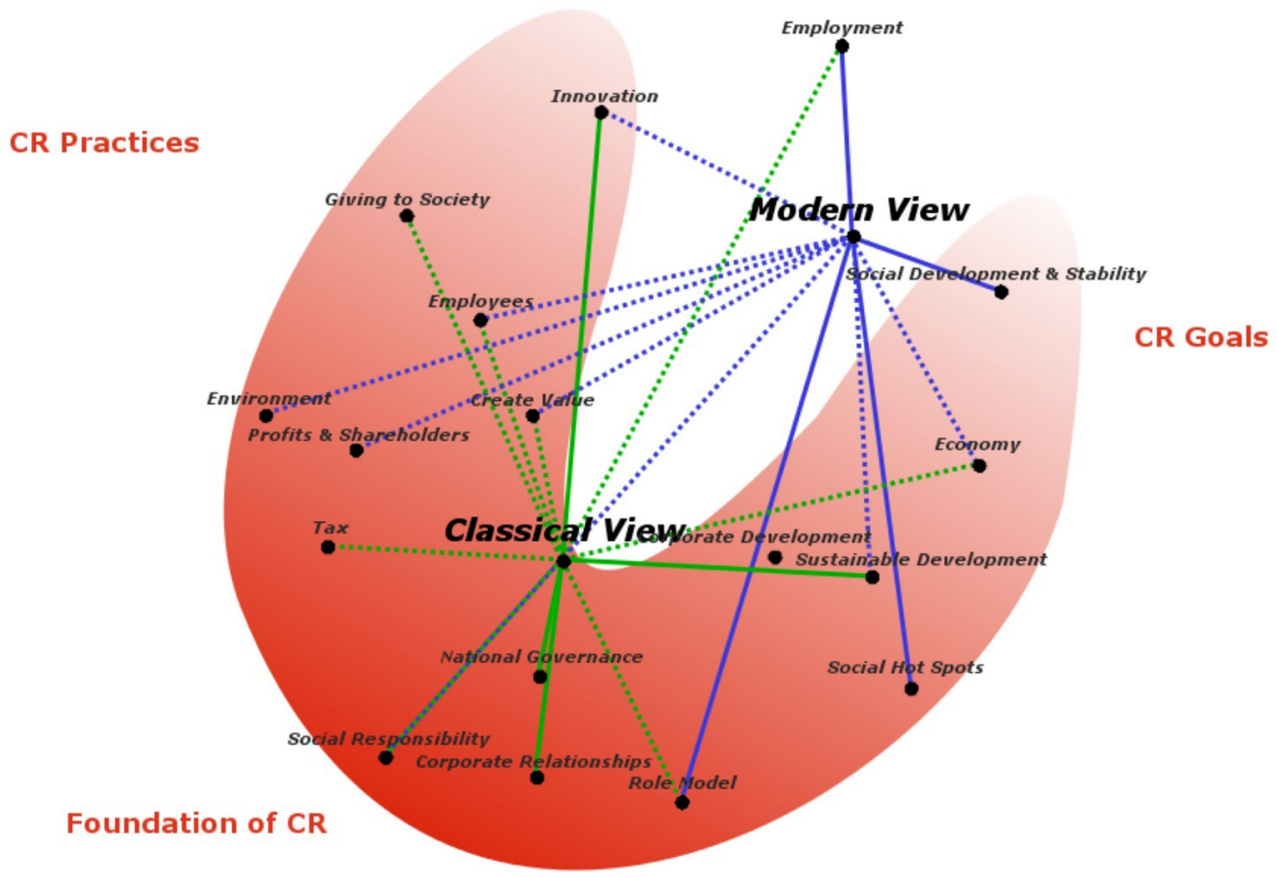


development in current practices and none in CR goals. The $\mathrm{CR}$ goals and practices are connected through the foundations of $\mathrm{CR}$, which refer to the understanding that corporations are part of a broad meta-system (i.e. the nation), which is essentially guided and managed by the Chinese government, and which is expected to foster both economic and social development.

The lines in Fig. 1 link thematic dimensions of corporate responsibility expectations based on the essays with the modern and the classical views according to Quazi and O'Brien (2000). By projecting the classical and the modern views onto this map, we find that they connect to CR practices and CR goals, as well as to economic and social development issues. To a lesser extent, they each lean toward a specific CR perspective: The modern view leans slightly toward CR goals, where CR is understood in terms social development and stability, overarching goals, especially related to employment, societal hot spots, such as corruption, and the national economy. Here, achieving these goals is in the interest of society as well as the corporation. Consequently, corporations benefit from their societal contribution. Here some examples from our essays:

- $[\ldots]$ being responsible to society can improve a corporation's image and reputation, which can help them gain social recognition and promote profit. (No. 75)

- Meanwhile, large corporations push the economy, technology, and people's livelihood forward, which will raise the corporations' social identity, and bring benefit to the corporations' development. (No. 6)

To a lesser extent, the modern view also connects to CR practices such as employees and value creation, innovation, the environment, and shareholder profits. Overall, the modern view represents the notion that corporations should be involved in CR programs aiming to achieve overarching societal goals through specific practices because these goals are also in their best interest. Notable with regard to the modern view is the distance to the governmental metasystem that is expected to regulate or present incentives to maintain the interdependence between economic and social development.

In contrast, the classical view is located in the area of corporate foundations and equidistant between CR practices and CR goals. Respondents holding this view regard corporations as part of a bigger, interdependent societal/ governmental system. They understand responsibilities of corporations in relation to this governmental meta-system. Here, large corporations are understood as an important national component, and they therefore have a responsibility to ensure the proper functioning of the nation as a whole. As the central member of this system, the state initiates, facilitates, and directs corporate engagement. Regulations do not play the role of restrictions and minimal standards but rather are guidelines designed to achieve overarching societal goals, which are in the best interest of society. Furthermore, corporations, as part of a national system, have the duty to not only follow the state's guidelines but also to take on the responsibilities resulting from their privileged position in the system, even if this comes at a cost. Here some examples from the essays:

- [...] fulfill its obligations as a legal entity. (No. 28)

- By 'responsibility', it means responsible to society, staff, suppliers, and purchasing agents. In my opinion, these responsibilities should be provided by legislation rather than corporations. The duty of corporations is to satisfy the requirements of regulators under the framework of legislation. (No. 2)

- For state-owned large corporations: represent the macroeconomics of the nation; practice the economic planning of the country; be the instrument of the government to adjust the economy; optimize the allocation of stateowned resources. (No. 63)

Because the $\mathrm{CR}$ foundations connect $\mathrm{CR}$ goals and $\mathrm{CR}$ practices, the classical view also connects to more than just economic goals and practices without giving preference to either. Overall, in the classical view, corporations are regarded as an essential part of the societal/governmental meta-system, which is guided by state regulations and laws, and which must fulfill their role within this system in order to achieve broader societal goals, even if this is related to costs and limitations in the short term.

\section{Discussion and conclusion}

Based on our analyses, we are able to draw three main conclusions. First, environmental concerns are mostly absent, appearing marginally only in association with current corporate pollution. They do not feature in CR-relevant goals. When they appear, they are clearly subordinated to national socioeconomic development. Second, the division of CR into a fourfold model of disparate and contrasting views as proposed by Quazi and O'Brien is inadequate for the Chinese context. Instead of opposing and incompatible views, we find different but highly integrated perspectives on CR. While those holding a modern view focus on overarching societal goals and the role of corporations in achieving them, those holding the classical view adopt a systemic approach in that corporations are an integral part of the societal/governmental system. Although different in character, the modern view and the classical view both stress the interdependence between economic and social development. Third, socioeconomic development is expected to be managed and regulated by a meta-system associated with government regulation, intervention, and incentives which, 
incidentally, is in line with the 2030 Agenda for Sustainable Development on the role of corporations.

According to our analyses, culture and context play a fundamental role in the understanding of CR in China. Culture-specific and context-sensitive nuances are difficult to capture in standardized questionnaires because, on the one hand, questionnaire items often reflect specific assumptions and contexts of (Western) researchers, and, on the other, the analyses of data and the interpretation of results are usually guided by context and culture-specific assumptions themselves, usually leading to misinterpretations and incorrect conclusions. In order to provide relevant and applicable frameworks for culture, context, and sector-specific CRrelated issues, we need to develop research instruments and techniques of analyses, which allow us to identify and describe more carefully the understandings of stakeholder positions across different cultures, contexts, industry sectors, and stakeholder groups. We are confident that with such an approach, a corridor of responsible corporate practices may be developed, which is embedded in a specific cultural and sociohistorical setting and yet compatible with international norms such as those upon which the United Nations Global Compact is based. What is of utmost importance is to identify one group of corporate practices that cannot be condoned under any circumstance in any cultural context because of its unsustainability or unethicality, another group of practices that is culture-specific but irrelevant to sustainability or fundamental ethics, and it should thus not be interfered with, and a third group, which requires careful culture and business-relevant stakeholder negotiations in order to define such a corridor.

Conflict of interest The authors declare that there are no actual or potential conflicts of interest in relation to this article.

\section{References}

Bergman MM (2010) Hermeneutic content analysis. Textual and audiovisual analyses within a mixed methods framework. In: Tashakkory A, Teddlie C (eds) SAGE handbook of mixed methods in social \& behavioral research, 2nd edn. SAGE, Los Angeles, pp 379-396

Bergman MM (2011) StudyCube. University of St. Gall, St. Gall

Bergman MM, Bergman Z, Gravett S (2011) The development and application of the explanatory model of school dysfunctions. S Afr J Educ 31(4):461-474

Bergman Z, Bergman MM, Liu B, Zhang J (2015) The roots of corporate philanthropy in China. J Int Bus Ethics 8(1):3-27

Boulger DC (1893) China. Collier \& Son, New York

Carroll AB (1991) The pyramid of corporate social responsibility: toward the moral management of organizational stakeholders. Bus Horiz 34(4):39-48

Ip PK (2009) Is Confucianism good for business ethics in China? J Bus Ethics 88(3):463-476

Lu X (2009) A Chinese perspective: business ethics in China now and in the future. J Bus Ethics 86(4):451-461

Peng S, Li L, Pan J, Han X, Hao D, Zhen M (2007) Enterprisers' recognition of enterprises' social responsibilities and the evaluation thereof - our report on the investigation of the special subject of the growth of China's enterprise managers in 2007-by the Survey System of China's Enterprisers. Manag World 6:83-93

Quazi AM, O'Brien D (2000) An empirical test of a cross-national model of corporate social responsibility. J Bus Ethics 25(1):33-51

Su R (2013) Behavior characteristic and regional difference of Chinese enterprise's CSR diffusion. Reform Econ Syst 2:112-115

Wang L, Juslin H (2009) The impact of Chinese culture on corporate social responsibility. The harmony approach. J Bus Ethics $88(3): 433-451$

Xu S, Yang R (2008) China's CSR has both common and unique dimensions as compared with Western CSR. China Economist, January, 127-136 